\title{
鄂尔多斯高原地区昆虫物种多样性研究
}

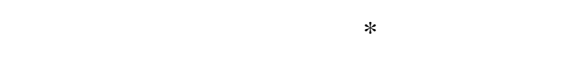

(中国科学院动物研究所, 北京 100080 )

摘要: 鄂尔多斯高原有特殊生境类型, 本文研究了该地区的昆虫物种多样性变化及影响因素,得到以下结果:(1) 利用巴氏罐诱法得到昆虫标本约 5159 号, 其他无脊椎动物标本 291 号, 鞘翅目为优势昆虫类群, 其数量占昆虫标本 总数的 $45.8 \%$, 其中拟步甲和步甲个体数量较多, 占所有甲虫总数的 $92.8 \% ; 2$; 根据甲虫的物种多样性和丰富度 的特点将 4 个调查地点分为两组:一组为以荒漠灌丛为主的杭锦旗和植被类型多样化的石灰庙,物种多样性指数、 丰富度和个体数量较高; 另一组为以人工植被区为主的石龙庙和新街镇,物种均匀度指数较高; (3) 主成分排序 (PCA) 可以将该地区的甲虫群落分为人工植被区和荒漠植被区 2 种类型, 反映降水和植被类型是决定甲虫群落组 成的关键因素; (4) 降水梯度对甲虫物种多样性有很大影响,物种多样性指数、均匀度指数与降水梯度呈显著的正 相关关系; 个体数量与降水梯度呈显著的负相关关系;物种的丰富度与降水梯度没有相关关系。以上结果表明,在 鄂尔多斯高原地区, 只有减少人为干扰, 加强保护脆弱的原有植被, 才能保护特有的昆虫种类; 只有大力开展固沙 造林植草, 才能改善环境, 提高该地区的昆虫物种多样性。

关键词：鄂尔多斯高原, 昆虫, 甲虫, 物种多样性, 降水梯度

中图分类号:Q968文献标识码：A 文章编号：1005-0094(2001)04-0329-07

\section{Species diversity of insects on the Ordos Plateau, Northwest China}

\author{
YU Xiao-Dong , ZHOU Hong-Zhang ${ }^{*}$, LUO Tian-Hong \\ Institute of Zoology, Chinese Academy of Sciences , Beijing 100080
}

\begin{abstract}
This study investigates characteristics and patterns of insect species diversity on the Ordos Plateau , a special ecotone with extremely arid environments in Northwest China. Using pitfall traps, we collected 5159 insect specimen and 291 other invertebrates. As the most dominant group , beetles accounted for $45.8 \%$ of the total collected insects , and among beetles , 92.8\% of individuals are Tenebrionidae and Carabidae. Plotting the $\log$ values of individual numbers of different beetle species , from high to low , results in patterns that separate the four investigated sites into two groups. One includes Hangjinqi, with mainly desert shrub environments, and Shihuimiao with a variety of habitats of different vegetation. The other includes Shilongmiao and Xinjiezhen with different environments, frequently artificial regeneration. The former exhibits high species diversity and richness, whereas the latter exhibits high evenness. Principal Component Analysis ( PCA) ordination of beetle communities indicates that the species distribution was determined by precipitation gradient and vegetation types. A positive correlation is seen between precipitation and beetle species diversity and evenness, while a negative correlation is one exhibited between precipitation and individual numbers. Species richness does not show such patterns. Thus, in an arid region as the Ordos Plateau, special insect species and their natural communities can be preserved only when the original vegetation is well protected and the disturbances of human activity are effectively limited. The environments in this region can be improved and a high insect diversity can be developed when regeneration is increased and drift sanddune is decreased in most parts of this region.
\end{abstract}

Key words : Ordos Plateau, insect, beetle, species diversity, precipitation gradient 
鄂尔多斯高原位于内蒙古自治区的南部,黄土 高原北沿, 以荒漠为主, 间杂一些农田或草地, 属于 荒漠半荒漠为主的高原地区, 地理位置为 $37.4^{\circ} \sim$ $40.8^{\circ} \mathrm{N}, 106.3^{\circ} \sim 112.2^{\circ} \mathrm{E}$ 。在气候上, 处于干旱 半干旱区向亚湿润区的过渡带; 在植被地带上来说， 处于荒漠草原一草原一森林草原的过渡带, 降雨量 自东南向西北逐渐减少 (张新时,1994)。从景观生 态学的角度看, 具有高度的景观异质性和多样性, 因 此鄂尔多斯高原地区是一个多层次的生态过渡带 多种生态类型交汇于此，且都处于临界状态，对外界 干扰相当敏感(王义凤等,1979;张新时,1994;陈仲 新, 谢海生, 1994;陈旭东等,1999)。鄂尔多斯高原 位于农牧交错带, 土地生态类型长期受到人类活动， 尤其是星荒和过度放牧的影响，导致该地区的荒漠 化加剧（董光荣等，1988），近年来，人们通过人工固 沙, 适地植树等活动改善鄂尔多斯高原的恶劣生态 环境，在靠近居民区附近出现了一定面积的树林。

昆虫作为物种丰富的门类, 其分布与环境有密 切关系, 可以用来监测环境的变化趋势 (Eyre et al. , $1996)$ 。但长期以来,这方面的工作没有得到相应 的重视。沙漠或荒漠昆虫的研究目前在我国还进行 得很少, 只在部分地区进行了群落结构、区系和分类 方面的研究(贺答汉等,1988; 孙宏义,1989;任国栋， 于有志,1999)。在鄂尔多斯高原，还没有进行过系 统的关于昆虫物种分布的本底资料调查。近年来, 人工固沙活动使该地区环境发生局部变化, 这种生 境变化对昆虫物种分布的影响也不得而知。

鉴于我国沙地昆虫研究的匮乏, 以及鄂尔多斯 高原的特殊地位和人为活动影响，本文主要研究鄂 尔多斯高原的昆虫物种组成、物种多样性以及影响 主要昆虫群落组成的因素, 希望能为沙地昆虫物种 多样性研究提供基本数据,为将来进一步研究打下 良好基础。

\section{1 研究样地与方法}

\section{1 研究地点}

我们的研究地点位于鄂尔多斯高原的东南部和 北部，分别代表人工固沙地带和荒漠地带。在人工 固沙地带的伊金霍洛旗的石龙庙、石灰庙和新街镇 选择典型生境设定 11 块样地，在荒漠为主的杭锦旗 设定 8 块样地, 样地每块长约 $50 \mathrm{~m}$,宽约 $20 \mathrm{~m}$ (图 1 ,表 1 )。

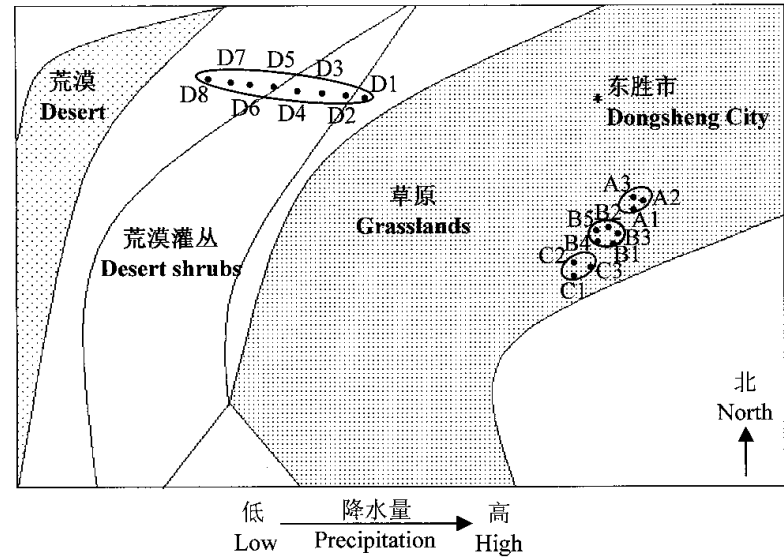

图 1 样地示意图(仿自陈旭东等,1999) 曲线代表降水梯度

$\mathrm{A} 1$ 沙地柏灌丛;A2 沙柳灌丛; $\mathrm{A} 3$ 羊柴灌丛;B1 柠条灌丛; B2 油䒾灌丛;B3 :本氏针茅 - 百里香灌丛;B4 :寸草苔;B5： 杨树林; C1 柳树林; C2 松树林; C3 棘豆灌丛; D1 :芨芨草 狭叶锦鸡儿灌丛;D2:白刺灌丛;D3 :油蕎灌丛 (受到人为破 坏 );D4 藏锦鸡儿灌丛;D5:甘蒙锦鸡儿 - 藏锦鸡儿灌丛; D6 红砂灌丛;D7 :四合木灌丛;D8 沙冬青灌丛

Fig. 1 The plots of insect investigation on the Ordos Plateau. Figure is modified from Chen et al. (1999)

The curves indicate the precipitation gradient

A1 : Sabina vulgaris shrubland ; A2 : Salix psammophyla shrubland ; A3 : Hedysarum laeve shrubland ; B1 : Caragana korshinskii shrubland; B2 : Artemisia ordosica shrubland; B3 : Stipa bungeana - Thymus serpyllum var. mongolicus shrubland ; B4: Carex duriuscula meadow ; B5 : Populus plantation; C1 : Salix plantation ; C2 : Pinus plantation ; C3 : Oxtropis shrubland ; D1 : Achnatherum splendens - Caragana stenophylla shrubland; D2 : Nitraria tangutorum shrubland; D3 : Artemisia ordosica shrubland (destroyed by shepherding) ; D4 : Caragana tibetica shrubland ; D5 : Caragana opulens - Caragana tibetica shrubland; D6 : Reaumuria soongorica shrubland ; D7 : Tetraena mongolica shrubland; D8 : Ammopiptanthus mongolicus shrubland

由于在伊金霍洛旗的人工固沙区人为干扰明 显,生境类型差异很大, 无法进行降水梯度对昆虫分 布影响的研究。而在杭锦旗的荒漠灌丛区,生境保 持原有状态, 人为干扰少, 是典型的荒漠半荒漠生 境, 海拔差异不大,适于进行降水梯度对昆虫分布影 响的研究。我们在杭锦旗约 $40^{\circ} \mathrm{N}$ 的纬度线上, 每 隔约 $10 \sim 20 \mathrm{~km}$ 设定样地, 共 8 块, 不同样地的降水 量根据张新时 (1994) 的经验公式推算：

$$
P=10^{\left(-45.3+22.8 \lg G+1894 / L^{2}+0.9 \times 10^{-7} \times H^{2}\right)}
$$

其中 $P$ 为降水量, $G$ 为经度, $L$ 为纬度, $H$ 为海拔高 度。在计算中我们发现，原公式中的对数形式为 $\ln$, 得出的数值与该地区的降雨量偏差极大, 而用 $\lg$ 形 式代替以后与真实的降雨量相符, 降水梯度约为 $138 \sim 281.2 \mathrm{~mm}$ (陈旭东等, 1999)。所以我们采用 $\lg$ 对数公式。 
表 1 调查样地的地理位置、海拔高度和降水量估算值

Table 1 The longitude, latitude, elevation and precipitation of plots on the Ordos Plateau

\begin{tabular}{|c|c|c|c|c|c|}
\hline $\begin{array}{c}\text { 地点 } \\
\text { Site }\end{array}$ & $\begin{array}{c}\text { 样地 } \\
\text { Plot }\end{array}$ & $\begin{array}{l}\text { 经度 } G \\
\text { Longitude }\end{array}$ & $\begin{array}{l}\text { 纬度 } L \\
\text { Latitude }\end{array}$ & $\begin{array}{c}\text { 海拔 } H \\
\text { Elevation }(\mathrm{m})\end{array}$ & $\begin{array}{c}\text { 降雨量 } P \\
\text { Precipitation }(\mathrm{mm})\end{array}$ \\
\hline \multirow{3}{*}{$\begin{array}{c}\text { 石龙庙 } \\
\text { Shilongmiao }\end{array}$} & $\mathrm{A} 1$ & $110^{\circ} 09^{\prime} \mathrm{E}$ & $39^{\circ} 28^{\prime} \mathrm{N}$ & 1270 & - \\
\hline & A2 & $110^{\circ} 11^{\prime} \mathrm{E}$ & $39^{\circ} 29^{\prime} \mathrm{N}$ & 1290 & - \\
\hline & A3 & $110^{\circ} 11^{\prime} \mathrm{E}$ & $39^{\circ} 29^{\prime} \mathrm{N}$ & 1290 & - \\
\hline \multirow{5}{*}{$\begin{array}{c}\text { 石灰庙 } \\
\text { Shihuimiao }\end{array}$} & B1 & $109^{\circ} 50^{\prime} \mathrm{E}$ & $39^{\circ} 22^{\prime} \mathrm{N}$ & 1330 & - \\
\hline & B2 & $109^{\circ} 50^{\prime} \mathrm{E}$ & $39^{\circ} 22^{\prime} \mathrm{N}$ & 1330 & - \\
\hline & B3 & $109^{\circ} 50^{\prime} \mathrm{E}$ & $39^{\circ} 22^{\prime} \mathrm{N}$ & 1340 & - \\
\hline & B4 & $109^{\circ} 50^{\prime} \mathrm{E}$ & $39^{\circ} 22^{\prime} \mathrm{N}$ & 1350 & - \\
\hline & B5 & $109^{\circ} 50^{\prime} \mathrm{E}$ & $39^{\circ} 22^{\prime} \mathrm{N}$ & 1340 & - \\
\hline \multirow{3}{*}{$\begin{array}{c}\text { 新街镇 } \\
\text { Xinjiezhen }\end{array}$} & C1 & $109^{\circ} 47^{\prime} \mathrm{E}$ & $39^{\circ} 13^{\prime} \mathrm{N}$ & 1295 & - \\
\hline & $\mathrm{C} 2$ & $109^{\circ} 47^{\prime} \mathrm{E}$ & $39^{\circ} 15^{\prime} \mathrm{N}$ & 1255 & - \\
\hline & C3 & $109^{\circ} 49^{\prime} \mathrm{E}$ & $39^{\circ} 16^{\prime} \mathrm{N}$ & 1325 & - \\
\hline \multirow{8}{*}{$\begin{array}{c}\text { 杭锦旗 } \\
\text { Hangjinqi }\end{array}$} & D1 & $108^{\circ} 28^{\prime} \mathrm{E}$ & $39^{\circ} 53^{\prime} \mathrm{N}$ & 1290 & 279 \\
\hline & D2 & $108^{\circ} 22^{\prime} \mathrm{E}$ & $39^{\circ} 54^{\prime} \mathrm{N}$ & 1280 & 271 \\
\hline & D3 & $108^{\circ} 08^{\prime} \mathrm{E}$ & $39^{\circ} 54^{\prime} \mathrm{N}$ & 1340 & 257 \\
\hline & D4 & $107^{\circ} 48^{\prime} \mathrm{E}$ & $40^{\circ} 03^{\prime} \mathrm{N}$ & 1230 & 229 \\
\hline & D5 & $107^{\circ} 34^{\prime} \mathrm{E}$ & $40^{\circ} 08^{\prime} \mathrm{N}$ & 1275 & 220 \\
\hline & D6 & $107^{\circ} 26^{\prime} \mathrm{E}$ & $40^{\circ} 09^{\prime} \mathrm{N}$ & 1285 & 215 \\
\hline & D7 & $107^{\circ} 15^{\prime} \mathrm{E}$ & $40^{\circ} 13^{\prime} \mathrm{N}$ & 1280 & 205 \\
\hline & D8 & $107^{\circ} 03^{\prime} \mathrm{E}$ & $40^{\circ} 13^{\prime} \mathrm{N}$ & 1280 & 197 \\
\hline
\end{tabular}

注:降水量的估算根据张新时 (1994) 的公式进行, 由于在检验降水量梯度影响时只考虑杭锦旗样地, 所以其他地区没有计算。表中字母所代 表的样地同图 1。

Note : Precipitation values were calculated based on the formula of Zhang (1994). The labels of plots are given in Fig. 1 ,

根据这个公式可以得到杭锦旗 8 个样地的降水 量 (表 1 ) ,由于油蒿灌丛受到人为破坏,所以在进行 群落排序和降水梯度与甲虫分布关系检验时不统计 在内。由于该地区为高原地区，昆虫尤其是甲虫的 活动有很强的季节性,所以我们选择昆虫的活动的 季节高峰 $7 \sim 8$ 月,于 1999 年进行野外采集调查。

\section{2 取样方法和标本鉴定}

调查主要采用巴氏罐诱法, 并结合扫网、灯诱等 采集方法（Martin，1978;Muehlenberg，1989），进行 全面的标本采集与数据收集。用一次性塑料水杯 (高 $9 \mathrm{~cm}$, 口径 $7.5 \mathrm{~cm}$ ) 作为巴氏罐诱法容器, 每块 样地内设诱杯 50 个, 诱杯间距约 $1 \mathrm{~m}$ 。引诱剂为 醋、糖、医用酒精和水的混合物,重量比为 $2: 1: 1$ : 20 , 每个诱杯内放引诱剂 $40 \sim 60 \mathrm{~mL}$ 。由于气温、 人为干扰程度、交通环境等因素影响，放置诱杯时间 $3 \sim 5$ 天左右。

标本初步鉴定依据 Bruce et al. (1954) 和 Freude et al. (1964) 的专著, 必要时对照中国科学 院动物研究所标本馆馆藏定名标本, 或由专家帮助 鉴定。

\section{3 数据分析处理}

物种多样性分析采用 Shannon-Wiener 多样性指
数,

$$
H^{\prime}=-\sum_{j=1}^{s} P_{j} \ln P_{j}
$$

$P_{j}=n_{j} / N$,为第 $j$ 种占总个体数 $N$ 的比例。均匀度 分析采用 Pielou 指数, $J=H^{\prime} / \ln S$ 。物种丰富度采用 物种数 $(S)$ 测度 (马克平, 刘玉明, 1992)。不同地区 甲虫物种的优势度 - 多样性曲线, 参照 Whittaker (1965) 的方法, 以物种数量等级排序 (以活动密度 从高到低的顺序排列) 为横轴, 以物种数量 (对数形 式) 为纵轴。

采用主成分分析 ( PCA, principal component analysis) 对 4 个地区的甲虫群落进行排序, 以各群落 内物种多样性指数、均匀度指数、丰富度指数和甲虫 个体的总量, 以及常见种的种类和数量为因子 (谭 济才等, 1998 鿰宝瑜,2000)。降水梯度与甲虫群落 的物种多样性指数、均匀度指数、丰富度以及个体数 量之间的数量关系通过回归检验 (Regression) 完成。

本研究的数据分析使用数理统计软件 SPSS (1997)。

\section{2 研究结果}

\section{1 主要类群及数量}

经过初步鉴定和数量统计, 本次野外采集共获 
标本 5450 号, 其中以昆虫标本为主, 约 5159 号; 其 他类群主要为多足纲动物及蛛形纲动物, 蜘蛛数量 略多些。表 2 列出包括昆虫在内的主要动物类群。 鞘翅目的标本数目最多，约为 2363 号。鞘翅目内又 以拟步甲科目最多, 有标本 1794 号, 步甲科次之, 有 标本 398 号, 这 2 个科为该地区的优势类群，占甲虫 总数的 $92.8 \%$ 。直翅目、双翅目、膜翅目也有相当 数量的分布。由于膜翅目的蚂蚁成聚群分布, 容易 在引诱中因为距离蚁巢的远近影响统计结果, 所以 没有进行精确的数量统计。

\section{2 甲虫物种多样性分析}

优势度 - 多样性曲线( 图 2 ) 表明可按物种丰富 度和多样性特点将 4 个地区分成 2 组: 石龙庙和新 街镇物种种类和数量都少, 整个曲线的斜率高, 物种 数量分布范围窄, 多样性程度低; 与之相对应, 石灰 庙和杭锦旗 2 个地区的物种种类和数量很多,曲线 的斜率低, 物种数量分布范围大, 多样性程度高。

从 4 个地区的比较看 物种多样性指数以石灰庙最 高 其次为杭锦旗、新街镇和石龙庙 均匀度指数以新街 镇最高，依次为石龙庙、石灰庙和杭锦旗。物种丰富度和 个体数量变化趋势相似, 杭锦旗最高, 依次为石灰庙、新 街镇和石龙庙, 且前两者远高于后两者 (表 3 )。

表 2 鄂尔多斯高原地区研究样地内捕获昆虫及其他无脊椎动物标本数量

Table 2 The number of specimens of insects and other invertebrates captured from the Ordos Plateau plots

\begin{tabular}{|c|c|c|c|c|c|c|c|c|c|c|c|c|c|c|c|c|c|c|c|}
\hline & \multicolumn{3}{|c|}{ 石龙庙 Shilongmiao } & \multicolumn{5}{|c|}{ 石灰庙 Shihuimiao } & \multicolumn{3}{|c|}{ 新街镇 Xinjiezhen } & \multicolumn{8}{|c|}{ 杭锦旗 Hangjinqi } \\
\hline & $\mathrm{A} 1$ & A2 & A3 & B1 & B2 & B3 & B4 & B5 & C1 & $\mathrm{C} 2$ & C3 & D1 & D2 & D3 & D4 & D5 & D6 & D7 & D8 \\
\hline 多足纲 Myriopoda & - & - & - & - & 2 & - & - & - & - & - & - & - & - & - & - & - & - & 1 & - \\
\hline 蛛形纲 Arachnida & & & & & & & & & & & & & & & & & & & \\
\hline 蜘蛛目 Araneida & 14 & 1 & - & - & 26 & 5 & 60 & 10 & 4 & 20 & 4 & 10 & 5 & - & 30 & 10 & 34 & 51 & - \\
\hline 蜱螨目 Acarina & - & - & - & - & - & - & - & - & - & - & - & - & - & - & - & - & 1 & 3 & - \\
\hline 昆虫纲 Insecta & & & & & & & & & & & & & & & & & & & \\
\hline 革翅目 Dermaptera & - & - & - & 10 & - & - & - & - & - & - & - & - & 18 & - & - & - & - & - & - \\
\hline 脉翅目 Neuroptera & - & - & - & 6 & - & - & - & - & - & - & - & 2 & 6 & - & 1 & 2 & 4 & 1 & - \\
\hline 直翅目 Orthoptera & 9 & - & - & 3 & 3 & 2 & 730 & 3 & - & 1 & 1 & 1 & 1 & - & 1 & - & - & - & - \\
\hline 同翅目 Homoptera & - & - & - & 5 & 30 & 110 & - & - & - & - & - & - & 5 & - & 7 & - & 39 & 19 & - \\
\hline 半翅目 Hemiptera & - & - & - & 8 & - & 1 & - & - & - & 1 & 3 & - & - & - & - & - & - & - & - \\
\hline
\end{tabular}

鞘翅目 Coleoptera

步甲科 Carabidae

大步甲属 Carabus

其他步甲 others

虎甲科 Cicindelidae

隐翅虫科 Staphylinidae

埋葬甲科 Silphidae

金龟科 Scarabaeidae

叶甲科 Chrysomelidae

天牛科 Cerambycidae

豆象科 Bruchidae

象甲科 Curculionidae

吒甲科 Elateridae

拟步甲科 Tenebrionidae

花蚤科 Mordellidae

伪叶甲科 Lagriidae

其他甲虫 Other beetles

膜翅目 Hymenoptera*

双翅目 Diptera

鳞翅目 Lepidoptera

蜻蜓目 Odonata

幼虫 Larva

$$
\begin{array}{cccccccccc}
2 & 7 & 1 & 23 & 13 & 33 & 172 & 22 & 1 & 5 \\
- & - & - & - & - & 1 & - & - & - & - \\
1 & - & 1 & - & - & - & - & - & - & - \\
1 & - & 1 & - & - & - & - & - & - & - \\
- & - & - & 3 & - & - & - & - & - & - \\
- & - & - & - & 27 & - & 1 & - & - & - \\
- & - & - & - & - & - & - & - & - & - \\
- & - & - & - & - & - & - & - & - & - \\
- & - & - & 1 & 2 & - & - & 24 & - & 1 \\
- & - & - & - & - & - & 1 & - & - & - \\
15 & 1 & - & 46 & 103 & 125 & - & - & 4 & 7 \\
- & - & - & - & - & - & - & 1 & - & - \\
- & - & - & - & - & - & - & 3 & - & - \\
- & - & - & - & - & - & - & 1 & - & 2 \\
3 & 1 & - & 9 & 10 & 49 & 10 & 9 & 1 & 4 \\
24 & 6 & - & 100 & 54 & 35 & 10 & 46 & 4 & 11 \\
- & - & - & 7 & 1 & 43 & - & 5 & 13 & -
\end{array}
$$$$
\begin{array}{llllllllll}
24 & 6 & - & 100 & 54 & 35 & 10 & 46 & 4 & 11
\end{array}
$$ 
表 3 鄂尔多斯高原地区 4 个地点甲虫物种多样性指数、均匀度指数、丰富度和个体数量

Table 3 Species diversity, evenness, richness and individuals of beetles collected from four sites on the Ordos Plateau

\begin{tabular}{lcccc}
\hline & 石龙庙 Shilongmiao & 石灰庙 Shihuimiao & 新街镇 Xinjiezhen & 杭锦旗 Hangjinqi \\
\hline 物种多样性指数 Diversity index $\left(H^{\prime}\right)$ & 0.73 & 1.41 & 0.89 & 1.04 \\
物种均匀度指数 Evenness index $(J)$ & 0.74 & 0.68 & 0.76 & 0.50 \\
物种丰富度 Richness $(S)$ & 3.00 & 8.40 & 3.67 & 8.43 \\
个体数量 No. of individuals & 9.33 & 120.20 & 10.33 & 212.57 \\
\hline
\end{tabular}

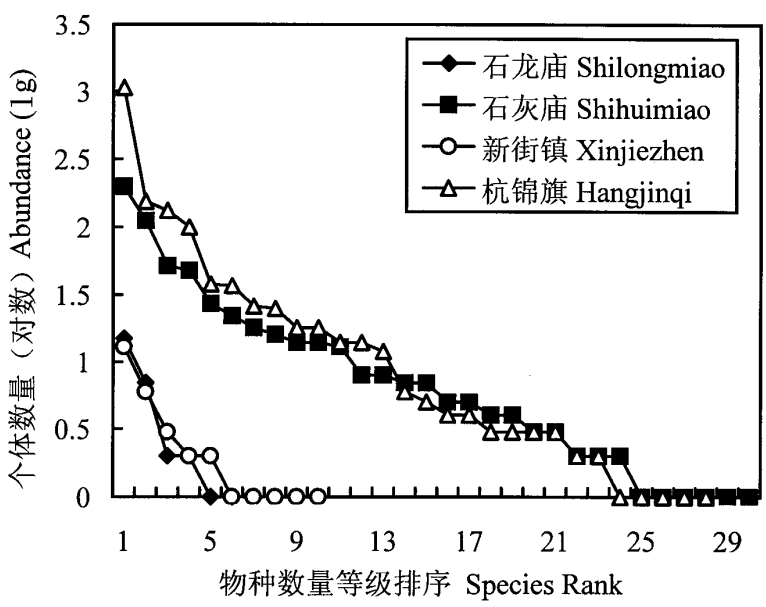

图 24 个地区甲虫物种的优势度 - 多样性曲线

物种数量排序按活动密度从高到低的顺序排列,物种的个体 数量以对数形式表示

Fig. 2 Dominance-diversity curves of the total number of beetles captured in all sites of four areas

Species are ranked from high to low activity-density on lg paper

\section{3 不同生境类型中主要甲虫类群群落排序}

18 个样地的甲虫群落的主成分排序见图 3。据 此可以将样地分成两大类:I 类主要为荒漠类型,包 括杭锦旗的 7 个沙地灌丛群落和石灰庙的油蒿和本 氏针茅 - 百里香 2 个低矮灌丛群落,代表相对干旱 少雨、沙化严重、植被低矮、覆盖率低的生境;II 类主 要为人工植被区,包括新街镇 3 个人工林、石龙庙的 3 个灌丛类型、石灰庙的 1 个草地类型和 2 个人工 植被类型，代表湿度较大或植被相对高大，覆盖率高 的生境。从以上排序可以看出, 决定甲虫群落类型 的主要因素是植被类型和降水，从群落类型 $\mathrm{I} \rightarrow \mathrm{II}$, 降水增加, 植被类型由适于生活在干旱、沙化程度高 的低矮灌丛过渡到生长在湿度相对较高、沙化相对 低的灌丛或人工林;甲虫的物种组成中, 荒漠化甲虫 如拟步甲，种类和数量减少，出现一些适于生活在湿 度较大生境中的甲虫类型，如步甲等。

\section{4 降水梯度和甲虫物种多样性}

降水梯度对甲虫群落的组成和数量变化有很大 影响。从图 4 可以看出, 物种多样性指数、均匀度指 数与降水梯度呈显著的正相关关系, 即随着降水量
的增高, 物种多样性指数和均匀度指数逐渐增高; 个 体数量与降水梯度呈显著的负相关关系, 即随着降 水量的增加,甲虫个体数量逐渐减少; 物种的丰富度 与降水梯度无关, 甲虫物种种类并没有随降水量增 加有显著的增多或减少。

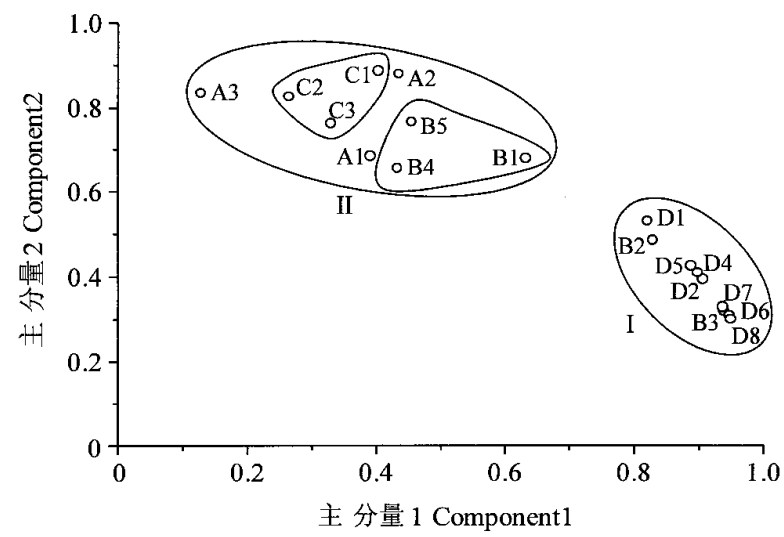

图 3 不同生境类型中甲虫群落的主成分分析排序 (PCA) 第一主分量贡献率为 $76 \%$, 第二主分量贡献率为 $11 \%$ 。图 中字母所代表的样地同图 1

Fig. 3 Principal component analysis (PCA) ordination of common beetle species captured from samples with different vegetation

Component 1 and Component 2 explained $76 \%$ and $11 \%$ variation respectively. The labels of plots are given in Fig. 1

\section{3 讨论}

鄂尔多斯高原地区景观异质性很强，包括湖泊、 农田、森林、草原、荒漠和流沙等景观,但就整体而 言, 主要以荒漠为主, 缺乏高大的森林生境和湿润的 草原生境,植被类型以耐旱生的灌丛类型为主, 单一 性很强, 不利于支持多种物种生存, 尤其不利于湿润 环境活动的昆虫物种。在我们的研究中, 选择鄂尔 多斯地区比较典型的生境, 样地主要为荒漠半荒漠 和人工植被区, 因此, 偏好干旱环境的甲虫就成为这 次调查采集中的主要昆虫类群, 如拟步甲科物种, 在 整个鄂尔多斯高原沙地的甲虫群落中占数量优势, 但整体来说物种种类和数量相对较少, 远低于森林 生态系统( 周红章等 2000)。 

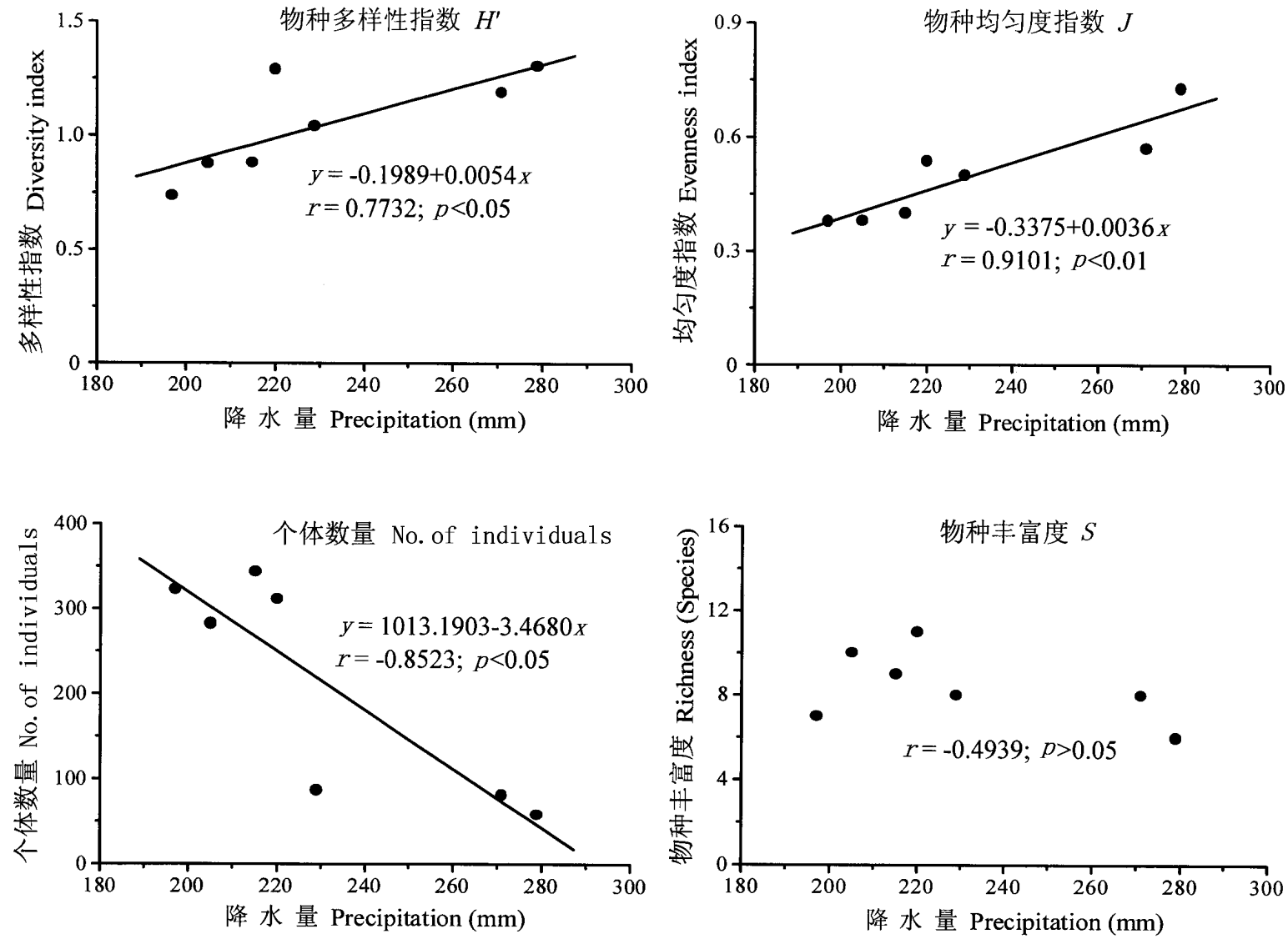

图 4 降水梯度 (不同生境类型) 与甲虫物种多样性指数、均匀度指数、丰富度和个体数量

Fig. 4 Changes in species diversity index, evenness index, richness and individual numbers of beetles along the precipitation gradient ( represented by plots of different habitats)

从鄂尔多斯地区的甲虫物种组成看，其种类和数 量分布与植被类型和降水梯度的变化有密切关系, 主 成分分析结果支持了这一结论。鄂尔多斯地区的降 水量由西北向东南逐渐递增，植被类型由单一的沙地 旱生灌木过渡到森林草原等多种植被生境, 与此相适 应, 甲虫物种应该向适应于湿度大、植被类型高大环 境的生活甲虫类型过渡。从我们的结果看, 4 个地点 的甲虫物种相似, 在湿度较大、植被类型较好的石龙 庙和新街镇,甲虫种类和数量非常低, 相反在湿度小、 植被荒漠化程度最高的杭锦旗却最丰富,但在与新街 镇毗邻的石灰庙的甲虫物种的丰富度和数量也相当 的高。究其原因, 我们认为,鄂尔多斯高原沙地整体 上属于荒漠区系，甲虫的组成比较单一，以适应干旱 环境的类群为主, 其组成和数量在不同植被类型的环 境下有所分化，植被类型较好的地区种类少、数量低， 荒漠化程度高的灌丛环境地区种类多、数量高。而且 由于森林生境主要为人工林, 天然化程度较低,人为 影响大, 缺乏发育良好的落叶腐质层, 环境的稳定性
相对较差, 不能支持较高的甲虫物种多样性 (Rosenzweig , 1995)。此外, 植被较好的草地 (寸草苔) 和人 工林,面积较小,大多被沙地或农田所包围, 呈斑块 化, 没有与东部草原或森林生境相连, 因为沙地形成 的隔离带不利于生活在草原或森林生境内的昆虫物 种向这些草地或人工林的扩散, 故这两种生境内甲虫 组成基本上来自沙地生境, 森林和草原成分较少, 而 且由于湿度较大, 不利于沙地甲虫生活, 以致于草地 和人工林的甲虫组成与其他荒漠生境相似, 但种类和 数量少得多,多样性程度较低。新街镇和石龙庙的生 境人工种植程度高, 均为居民的主要聚居地, 人为干 扰强; 石灰庙生境复杂，既包括寸草苔、杨树林和柠条 灌丛等人工植被, 也有野生的适于干旱荒漠化的本氏 针茅 - 百里香灌丛和油蒿灌丛 杭锦旗是典型的荒漠 灌丛生境。与这些生境特点相适应, 通过主成分分析 排序可以看出，石灰庙的油蒿灌丛和本氏针茅 - 百里 香灌丛与杭锦旗的 7 种灌丛类型的甲虫组成和数量 分布相似，新街镇、石龙庙及石灰庙的其他 3 种生境 
的物种组成和数量分布相似。

从降水梯度看, 甲虫的物种多样性指数和均匀度 指数都与降水量呈正相关, 但个体数量与降水量呈负 相关，丰富度与降水量没有相关关系。这正好反映了 荒漠沙地的甲虫组成特点, 尤其是降水梯度实验环境 为典型荒漠性环境, 海拔变化不大。没有空间隔离， 甲虫可以自由扩散，所以在整个梯度环境内的甲虫物 种组成差异不大，由于降水梯度不同，对于偏好干旱 性甲虫的数量分布有显著影响, 湿度大, 个体数量反 而少, 优势种程度降低, 物种多样性和均匀度指数增 高。

孙宏义 (1989) 在沙坡头研究昆虫区系时,将沙 地分成流沙区、沙地人工植被区和沙地农业改良利用 区。我们所选的植被类型没有流沙区类型，杭锦旗植 被最为接近流沙和人工植被区, 但杭锦旗的昆虫组成 与沙坡头的流沙区更为接近，拟步甲为优势种，表明 干旱程度很高; 而在沙坡头人工植被区和沙地农业改 良利用区主要甲虫类型为虎甲、步甲等甲虫, 这与石 龙庙、石灰庙的人工林或寸草苔以及石龙庙的人工植 被区昆虫组成相似，表明鄂尔多斯地区人工植被区的 人为影响很大, 而且, 虽然在整体上人工植被区的甲 虫组成与荒漠区相似, 但某些科的甲虫, 如隐翅虫科、 埋葬甲科、伪叶甲科等, 有少量个体分布, 说明人工植 被区昆虫有更广的生态适应，与荒漠生境类型的甲虫 组成有初步的分化。

以上结果表明, 鄂尔多斯高原沙地昆虫主要为适 于生活在干旱环境下的甲虫类群, 由于环境单一, 甲 虫物种分布差异不大, 而数量分布与植被类型和降水 梯度密切相关。虽然该地区进行的人工固沙工作很 有成效，使该区的昆虫种类向更广的趋势演化，但由 于面积太小, 人为干扰程度高, 人工植被未能天然化， 且与东部的森林和草原生境相距较远, 并不能对甲虫 群落的种类组成有很大改变, 甚至在某种程度上还降 低了甲虫的数量, 所以, 只有加大固沙力度, 扩大改良 环境的面积, 植树种草, 大力促进人工植被的天然化， 增加植物的物种多样性，在空间配置上提高景观多样 性, 同时尽量减少人为干扰活动, 才能真正丰富该地 区的昆虫物种多样性。

致谢 在我们的野外昆虫采集过程中, 得到中国科学 院植物所的张明理博士和陈旭东博士的大力协助, 特
此表示感谢。同时感谢中国科学院动物所的李鸿兴 先生帮助鉴定了部分标本。

\section{参考文献}

陈旭东, 董学军, 陈仲新, 1999. 鄂尔多斯高原沙地灌丛生物多 样性及重建生态学研究. 见: 马克平(主编), 中国重点地 区与类型生态系统多样性. 杭州: 浙江科学技术出版社, $109 \sim 153$

陈仲新, 谢海生, 1994. 毛乌素沙地景观生态类型与灌丛生物 多样性初步研究. 生态学报, 14 (4): 345 354

董光荣, 高尚玉, 金畑, 李保生, 1988. 毛乌素沙漠的形成、演变 和成因问题. 中国科学 (B 辑), 18 (6): 633 642

韩宝瑜, 2001. 马尾松林节肢动物群落的组成及多样性. 生物 多样性, 9 (1): $62 \sim 67$

贺答汉, 田畴, 任国栋, 郝峰茂, 马世渝, 1988. 荒漠草原昆虫的 群落结构及其演替规律初探. 中国草地, 11 (6) : 24 28

马克平, 刘玉明, 1994. 生物群落多样性的测度方法 I: $\alpha$ 多样 性的测度方法(下). 生物多样性, 2 (4) : 231 239

任国栋, 于有志, 1999. 中国荒漠半荒漠的拟步甲科昆虫. 保 定: 河北大学出版社

孙宏义, 1989. 沙坡头昆虫区系初步研究. 中国沙漠,9 (2) : 71 $\sim 81$

谭济才, 邓欣, 袁哲明, 1998. 不同类型茶园昆虫、蜘蛛群落结 构分析. 生态学报, 18 (3): 289 294

王义风, 雍世鹏, 刘钟龄, 1979. 内蒙古草原植被的地带性特 征. 植物学报, 21 (3): 274 284

张新时, 1994. 毛乌素沙地的生态背景及其草地建设的原则与 优化模式. 植物生态学报, 18 (1): $1 \sim 16$

周红章, 于晓东, 罗天宏, 何君舰, 周海生, 叶婵娟, 2000. 湖北 神农架自然保护区昆虫的数量变化与环境关系的初步研 究. 生物多样性, 8 (3): 262 270

Bruce C T, Melander A L, Carpenter F M 著, 1954. 肖采瑜, 程 振衡, 尚雅珍, 郑乐怡 (译), 1959. 昆虫的分类. 北京: 科学 出版社

Eyre M D, Lott D A and Garside A, 1996. Assessing the potential for environmental monitoring using ground beetles (Coleoptera: Carabidae) with riverside and Scottish data. Annales Zoologici Fennici, 33: $157 \sim 163$

Freude H, Harde K W and Lohse G, 1964. Die Kaefer Mitteleuropas ( Bd. $2 \sim 12$ ). Krefeld: Goecke \& Evers

Martin J E H, 1978. The insects and arachnids of Canada ( Part 1: Collecting, preparing and preserving insects, mites, and spiders). Hull, Quebec: Supply and Services Canada

Muehlenberg M, 1989. Freilandoekologie. Heidelberg: Quelle \& Meyer Verlag

Rosenzweig M L, 1995. Species Diversity in Space and Time. Cambridge: Cambridge University Press

SPSS Inc, 1997. SPSS Base 7.5 for Windows user's guide

Whittaker R H, 1965. Dominance and diversity in land plant communities. Science, 147: $250 \sim 260$ 